Article

\title{
Comparative Analysis of Actaea Chloroplast Genomes and Molecular Marker Development for the Identification of Authentic Cimicifugae Rhizoma
}

\author{
Inkyu Park $\mathbb{D}^{\mathbb{2}}$, Jun-Ho Song $\mathbb{D}^{\mathbb{D}}$, Sungyu Yang and Byeong Cheol Moon * \\ Herbal Medicine Resources Research Center, Korea Institute of Oriental Medicine, Naju 58245, Korea; \\ pik6885@kiom.re.kr (I.P.); songjh@kiom.re.kr (J.-H.S.); sgyang81@kiom.re.kr (S.Y.) \\ * Correspondence: bcmoon@kiom.re.kr; Tel.: +82-61-338-7100
}

Received: 26 December 2019; Accepted: 24 January 2020; Published: 27 January 2020

\begin{abstract}
Actaea (Ranunculaceae; syn. Cimicifuga) is a controversial and complex genus. Dried rhizomes of Actaea species are used as Korean traditional herbal medicine. Although Actaea species are valuable, given their taxonomic classification and medicinal properties, sequence information of Actaea species is limited. In this study, we determined the complete chloroplast (cp) genome sequences of three Actaea species, including A. simplex, A. dahurica, and A. biternata. The cp genomes of these species varied in length from 159,523 to 159,789 bp and contained 112 unique functional genes, including 78 protein-coding genes, 30 transfer RNA genes, and 4 ribosomal RNA genes. Gene order, orientation, and content were well conserved in the three cp genomes. Comparative sequence analysis revealed the presence of hotspots, including $n d h C-t r n V-U A C$, in Actaea cp genomes. High-resolution phylogenetic relationships were established among Actaea species based on cp genome sequences. Actaea species were clustered into each Actaea section, consistent with the Angiosperm Phylogeny Group (APG) IV system of classification. We also developed a novel indel marker, based on copy number variation of tandem repeats, to facilitate the authentication of the herbal medicine Cimicifugae Rhizoma. The availability Actaea cp genomes will provide abundant information for the taxonomic and phylogenetic analyses of Actaea species, and the Actaea (ACT) indel marker will be useful for the authentication of the herbal medicine.
\end{abstract}

Keywords: Actaea; Cimicifuga; plastid; indel marker; herbal medicine

\section{Introduction}

Chloroplasts play an essential role in photosynthesis and carbon fixation [1]. In angiosperms, chloroplast (cp) genomes range in size from $115-180 \mathrm{~kb}$ and exhibit a quadripartite structure consisting of two single copy, a large single copy (LSC) region, a small single copy (SSC) region, and two copies of an inverted (IR) region (IRa and IRb) [2,3]. In general, cp genomes of angiosperms contain 110-130 genes, with up to 80 protein-coding genes, 30 transfer RNA (tRNA) genes, and 4 ribosomal RNA (rRNA) genes [1]. The structure of the cp genome is highly conserved among plant species compared with that of nuclear and mitochondrial genomes [4]. Moreover, cp genomes exhibit maternal inheritance, thus facilitating the conservation of gene contents and genome structure $[5,6]$. Consequently, the $c p$ genome is widely used for species identification, molecular marker development, evolutionary analysis and high-resolution phylogenetic analysis [7-9]. With advances in next-generation sequencing, the cost of cp genome assembly has decreased, while the speed of sequencing has increased [8]. Moreover, cp genome sequencing represents a viable alternative to DNA barcoding, a controversial method of species identification. Recently, complete cp genomes have been reported for four Actaea species, including A. heracleifolia, A. dahurica, A. vaginata, and A. asiatica [10,11]. Genomic information available 
for Actaea species identification is limited, and additional genomic information is needed to understand the utility of Actaea phylogeny and the evolutionary relationship among the Actaea species.

The genus Actaea L. (including Cimicifuga L. ex Wernisch. and Souliea Franch.) comprises approximately 27 species, which show a wide distribution in Asia, Eurasia, and North America [12]. Plants of Actaea species are perennial herbs, with racemose or paniculate inflorescences that bear many actinomorphic flowers with free carpels and follicular or baccate (berry-like) fruits [13]. However, the classification of Actaea and its related genera remains controversial. Compton et al. merged Actaea and Cimicifuga with Souliea based on sequence information of the internal transcribed spacer (ITS) region and the trnL-F gene [12]. Moreover, Compton et al. [12] identified seven sections within the genus Actaea. However, Wang et al. [14] proposed that Actaea, Cimicifuga, and Souliea were independent genera, based on the morphological, palynological, and cytological characteristics of these plant species. Actaea and Cimicifuga are currently recognized as members of the tribe Cimicifugeae [15,16]. Phylogenetic analysis based on the nuclear ITS region and cp loci revealed that Actaea and Cimicifuga form a monophyletic group [12,17,18]. The genetic relationship of Actaea and Cimicifuga with the closest genus Eranthis is highly similar. Thus, Actaea and Cimicifuga are together recognized as the genus Actaea, which was formed by merging Cimicifuga with Souliea [12].

Dried rhizomes of $A$. simplex, A. dahurica, and A. heracleifolia are used as a Korean traditional herbal medicine, namely, Cimicifugae Rhizoma, which is recognized as a medicine in the Korean Herbal Pharmacopoeia [19]. Cimicifugae Rhizoma is controlled by the Ministry of Food and Drug Safety due to its pharmaceutical properties [20-22]. Only the rhizomes of A. simplex, A. dahurica, and A. heracleifolia are considered as authentic Cimicifugae Rhizoma in Korea [19]. However, rhizomes of other Actaea species such as A. biternata and A. asiatica, which are also distributed in Korea [12,19], are morphologically highly similar to those of $A$. simplex, A. dahurica, and A. heracleifolia to the naked eye. Consequently, Cimicifugae Rhizoma has been adulterated with closely related other Actaea species in Korean herbal markets [23]. Thus, authentication of Actaea species is important for preserving a uniform pharmacological effect of Cimicifugae Rhizoma.

In this study, we determined and characterized the cp genomes of three follicular Actaea species, including A. simplex, A. dahurica, and A. biternata, and compared these sequences with the cp genome sequences of three additional Actaea species. Phylogenetic analysis was performed to establish the genetic relationships of Actaea species within Cimicifugeae. Moreover, we developed a novel indel marker to authenticate Cimicifugae Rhizoma as a herbal medicine. Our results contribute available data for the authentication of Cimicifugae Rhizoma, based on genomic features, which will help preserve the quality of this herbal medicine. Moreover, our results provide key insights into the evolution of species within Cimicifugeae.

\section{Results and Discussion}

\subsection{Features of the cp Genomes of Three Actaea Species}

Sequencing of the cp genomes of three Actaea species including A. simplex, A. dahurica, and $A$. biternata at approximately $31 \times, 74 \times$, and $280 \times$ coverage, respectively, generated $2.1-2.3$ $\mathrm{Gb}$ raw paired-end read data, which was equivalent to 1.4-1.7 Gb trimmed reads (Table S1). The cp genomes of all three Actaea species were of high quality (Figure 1, Table 1). The complete cp genome sequences of the three Actaea species varied in length from 159,523-159,789 bp and showed a typical quadripartite structure, with the LSC region of $88,723,88,652$, and $88,958 \mathrm{bp}$, SSC region of 17,865 , 17,729 , and $17,757 \mathrm{bp}$ and each IR region of $26,518,26,571$, and $26,537 \mathrm{bp}$ in A. simplex, A. dahurica, and A. biternata, respectively. Junction regions in the cp genome of each species were validated by PCR-based sequencing (Table S2, Table S3). In addition, the sequence reads were validated by mapping them onto the complete cp genomes (Figure S1). The GC content of the cp genome of each species was approximately $38 \%$ (Table 1). In general, the GC content of IRs was higher than that of single copy regions in all three species $[10,11]$. Gene content and gene order were highly similar among the 
three Actaea species. The cp genome of each Actaea species harbored 112 unique genes, including 78 protein-coding genes, 4 rRNA genes, and 30 tRNA genes (Table 1, Table S4). The cp genomes of Actaea species exhibited duplicate genes in the IR regions. In all three cp genomes, rpl32 (large ribosomal protein 32) was a pseudogene, with partial deletion. This was consistent with a previous report of the loss or pseudogenization of $r p l 32$ within Ranunculaceae [11]. In the tribe Isopyreae, $r p l 32$ from the $\mathrm{cp}$ genome was integrated into the nuclear genome, demonstrating gene transfers from an organelle genome to the nuclear genome [11,24]. A total of 17 intron-containing genes were detected in the $3 \mathrm{cp}$ genomes, including 11 protein-coding genes, 6 tRNA genes harboring a single intron and 2 genes (ycf3 and $\operatorname{clpP}$ ) harboring 2 introns (Table S5). The cp genomes of all three Actaea species showed a stable and typical quadripartite structure similar to that of other angiosperms [25-27]. The genome length, gene content, gene orientation, and GC content of the three Actaea cp genomes were similar to those of genera within Cimicifugeae [11]. Analysis of codon usage and anticodon recognition patterns revealed that the three Actaea cp genomes contained 26,669-26,696 codons and codons for leucine (Leu), isoleucine (Ile), and serine (Ser) were the most abundant (Figure S2A). The value of relative synonymous codon usage (RSCU) was greater than 5 for arginine (Arg), Leu and Ser, as expected (Figure S2B). The RSCU values represented synonymous codon bias with a high proportion of A or T at the third position, similar to the cp genomes of other angiosperms [28-30]. The amino acid of high RSCU values infers that the contribution functionally prevents error in the peptide or transcription process $[28,30]$. Overall, the characterization of three Actaea cp genomes showed that these genomes are highly conserved, similar to the cp genomes of other Actaea species [10,11].

Table 1. Characterization of the cp genomes of three Actaea species.

\begin{tabular}{cccc}
\hline Characteristics- & A. Simplex & A. Dahurica & A. Biternata \\
\hline GenBank accession number & MN623225 & MN623226 & MN623227 \\
Chloroplast genome size (bp) & 159,624 & 159,523 & 159,789 \\
Large single copy (LSC) region (bp) & 88,773 & 88,041 & 88,083 \\
Inverted repeat (IR) region (bp) & 26,518 & 26,571 & 26,537 \\
Small single copy (SSC) region (bp) & 17,865 & 17,729 & 17,757 \\
Total number of genes & 112 & 112 & 112 \\
Number of protein-coding genes & 78 & 78 & 78 \\
Number of rRNA genes & 4 & 4 & 4 \\
Number of tRNA genes & 30 & 30 & 30 \\
GC content (\%) & 38.1 & 38.1 & 38.1 \\
LSC (\%) & 36.2 & 36.3 & 36.2 \\
IR (\%) & 43.1 & 43.1 & 43.1 \\
SSC (\%) & 32.3 & 32.4 & 32.3 \\
\hline
\end{tabular}

\subsection{Repeat Sequences in cp Genomes of Three Actaea Species}

SSRs are abundant in nuclear and organelle genomes and used in phylogenetic analysis and population genetics because of their stability and transferability [31,32]. A total of 168, 172, and 183 SSRs were detected in A. simplex, A. dahurica, and A. biternata cp genomes, respectively, using the Microsatellite Identification Tool (MISA) program [33] (Figure S3). The number of SSRs per unit length was higher in the single copy (SC) regions (LSC and SSC) than in IR regions in all three Actaea species. The cp genome of $A$. biternata contained numerous SSRs in IR regions compared with other Actaea species (Figure S3). The intergenic spacer (IGS) regions and exons in cp genomes contained monoand dinucleotide SSRs. Tandem repeat sequences influenced the genomic structure variation and gene duplication and were often used for developing indel markers because of their copy number variation [4,27]. We surveyed tandem repeat sequences in cp genomes of Actaea species using the Tandem Repeats Finder program [34]. We detected 21, 23, and 20 tandem repeats in more $20 \mathrm{bp}$ of A. simplex (Table S6), A. dahurica (Table S7), and A. biternata (Table S8), respectively. These tandem repeats were $8-46 \mathrm{bp}$ in length and were present as $2-4$ copies in the three Actaea cp genomes (Tables 
S6-S8). The majority of tandem repeats were located in the LSC region. We used these tandem repeats, particularly those in rps16-trnQ-UUG, for the development of an indel marker to identify authentic Cimicifugae Rhizoma.

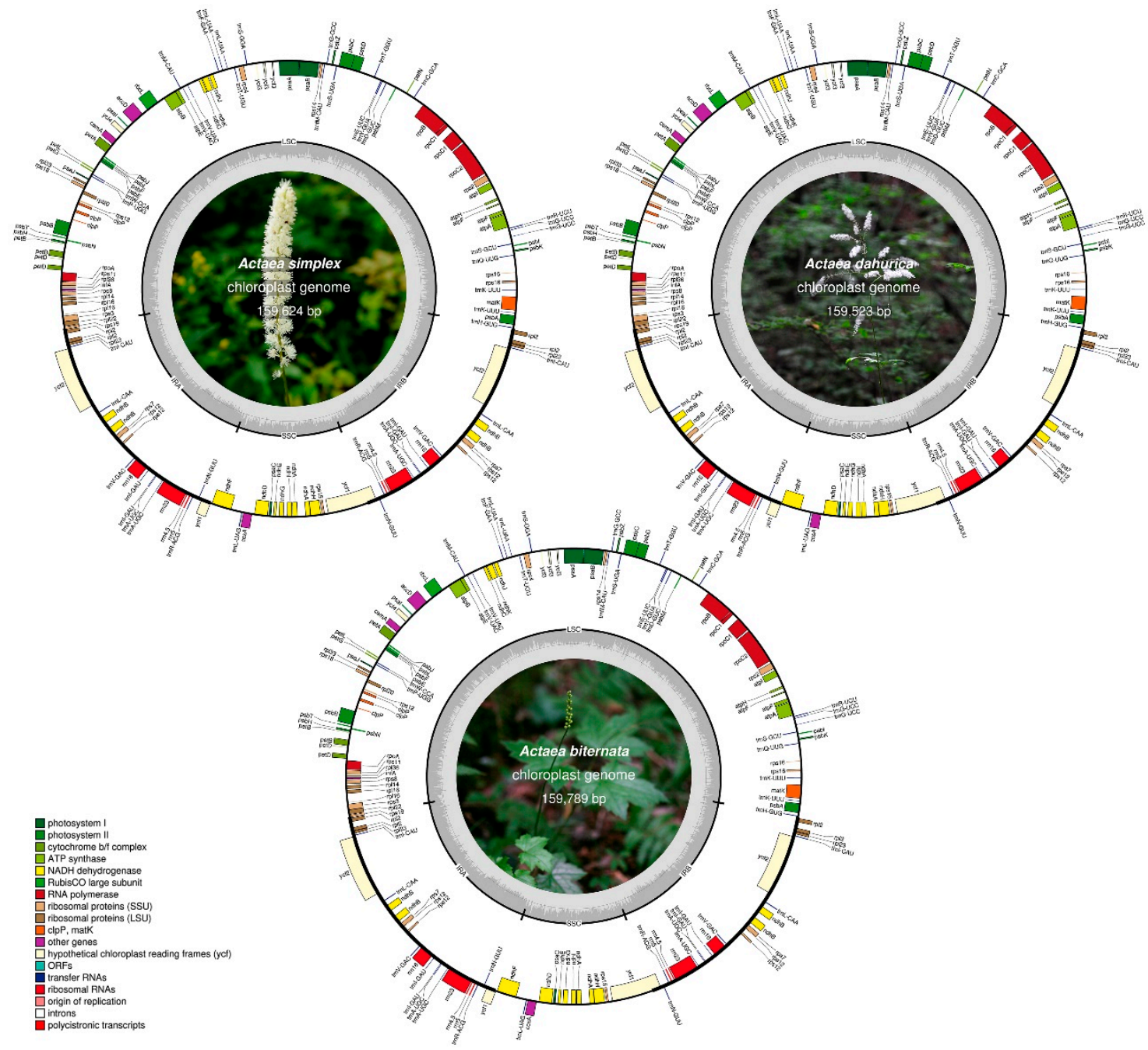

Figure 1. Graphical maps of the $\mathrm{cp}$ genomes of A. simplex, A. dahurica, and A. biternata. Genes drawn inside the outermost circle are transcribed clockwise, and those outside the circle are transcribed counterclockwise. Dark gray shading in the inner circle indicates the GC content. The inner photograph shows Actaea.

\subsection{Structure of cp Genomes of Actaea Species}

To investigate divergence within the genus Actaea, we compared the structure of cp genomes of six Actaea species including A. simplex, A. dahurica, A. biternata, A. heracleifolia, A. asiatica, and $A$. vaginata; cp genomes of the latter three species, A. heracleifolia (NC_042253), A. asiatica (NC_041525), and A. vaginata (NC_041543), were downloaded from GenBank database of the National Center for Biotechnology Information (NCBI). All six Actaea species showed greater divergence in the SC regions (LSC and SSC) than in the IR regions. The majority of divergent sequences were located in the IGS regions. In genic regions, $m a t K, y c f 1$, and $y c f 2$ showed greater divergence than other genes; this is consistent with previous studies [35-37]. The matK gene harbors an important DNA barcode region for species identification [35]. All six Actaea species showed divergence in three regions including trnC-GCA-petN, ndhC-trnV-UAC, and ycf1-ndhF. Additionally, A. biternata and A. asiatica showed high divergence in the region from pet $B$ to pet $D$ (Figure 2). Divergence in the $n d h C-t r n V-U A C$ region, known as the hotspot region, has been detected in the cp genomes of other angiosperms [36,37]. These 
regions represent potential candidates for molecular marker development for species identification. We analyzed syntenic regions in Actaea species using the MAUVE algorithm. The cp genomes of all six Actaea species formed a well-conserved collinear block (Figure S4), thus showing a highly conserved structure.

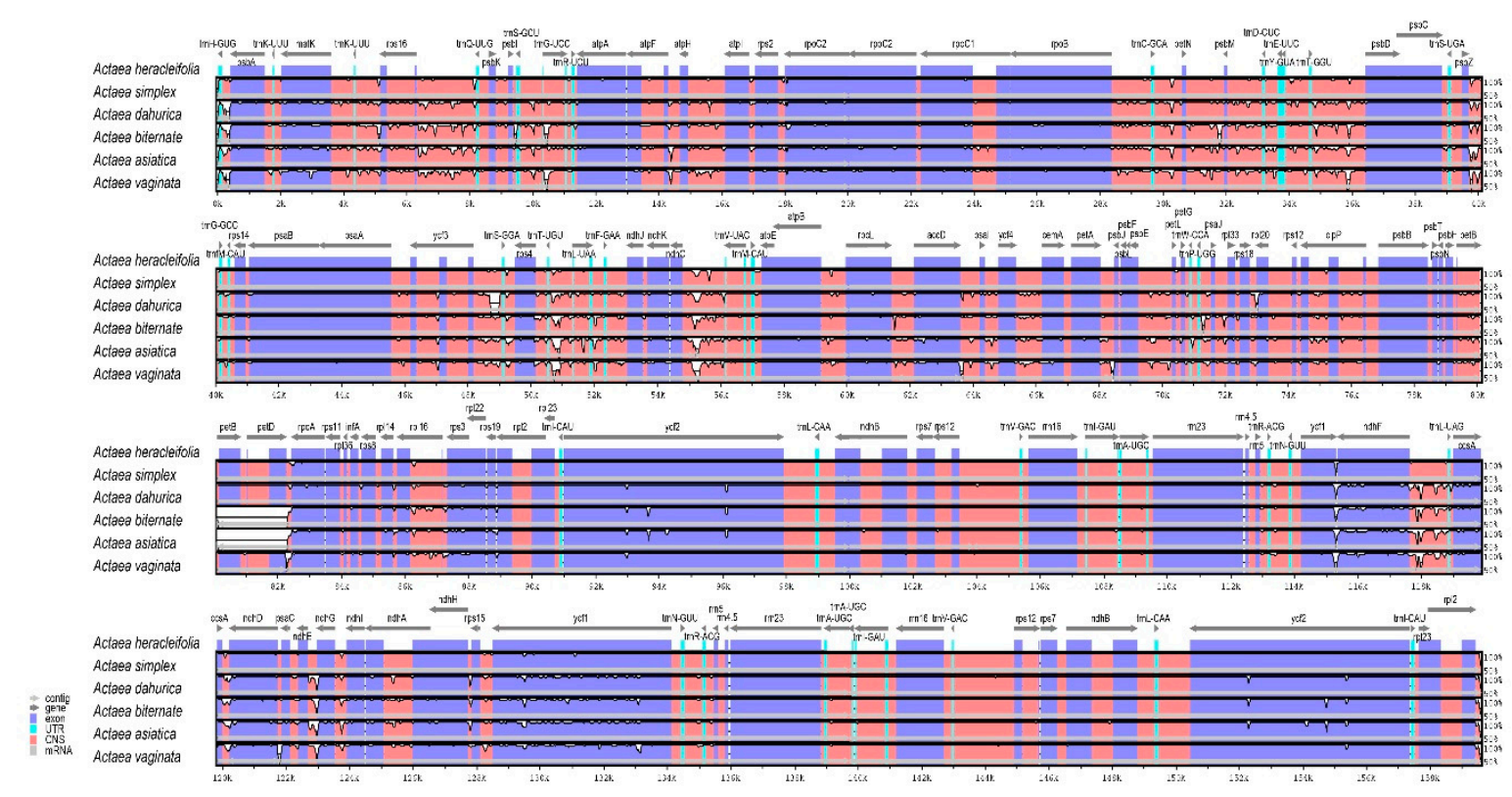

Figure 2. Comparative analysis of the cp genomes of six Actaea species, including A. simplex, A. dahurica, A. biternata, A. heracleifolia, $A$. asiatica, and $A$. vaginata, using mVISTA. The cp genome of $A$. heracleifolia used as a reference. Blue blocks, conserved genes; sky-blue blocks, tRNA and rRNA genes; red blocks, conserved non-coding sequences (CNSs); white blocks, regions polymorphic among the six Actaea species. A cut-off of $50 \%$ identity was used for the plots. The Y-axis represents a $50 \%-100 \%$ identity.

To determine sequence divergence in the six Actaea cp genomes, we calculated the nucleotide diversity $(P i)$ (Figure 3). The total value of $P i$ for all six Actaea species at the cp genome level was 0.0104. The IR regions showed greater conservation than the SC regions, with average pi values of 0.0027 and 0.0234 , respectively. The IGS region in $n d h C$-trnV-UAC showed high divergence, with a $P i$ of 0.0418 . In the genic region, the value of $P i$ for $n d h F$ was 0.01254 , indicating that the genic region was more highly conserved than the IGS region, as expected. In this study, although the cp genomes of all six Actaea species showed a highly conserved structure, high sequence variability was detected at the genus level. The IR/SC border regions were highly conserved among the six Actaea species (Figure S5). The rps19 genes of the three Actaea were located at the LSC/IRa region. The ycf1 pseudogene and ycf1 gene were located in the junction of IRa/SSC and SSC/IRb. The trnH-GUG genes were all located in the LSC region. Overall, cp genomes of all the six Actaea species showed a consistent structure. To identify genetic variation among the six species, we analyzed the non-synonymous to synonymous substitution ratio $(\mathrm{Ka} / \mathrm{Ks})$ using $67 \mathrm{cp}$ genes conserved among $A$. simplex, $A$. dahurica, and $A$. biternata (Figure S6). Most of these genes were under purifying selection $(\mathrm{Ka} / \mathrm{Ks} \leq 0)$. The $a c c D$ gene showed a $\mathrm{Ka} / \mathrm{Ks}$ ratio of 2.156 in comparison with $A$. dahurica and $A$. biternata, while the $y c f 2$ gene showed a $\mathrm{Ka} / \mathrm{Ks}$ ratio of 1.167 in comparison with $A$. simplex and $A$. biternata, implying that acc $D$ and $y c f 2$ were under positive selection, which led to greater environmental adaptation. The $a c c D$ gene encodes acetyl-CoA carboxylase, a key enzyme that catalyzes the carboxylation of acetyl-CoA to produce malonyl-CoA [1]. Several species have lost the $a c c D$ gene from their cp genomes, but the function of $a c c D$ performed in the nuclear genome, performs the same function as $a c c D$. [7,38]. Positive selection of $a c c D$ and $y c f 2$ genes has been reported in the cp genomes of other species within the genera Ipomoea, Anemopaegma, and Amphilophium [27,39,40]. Furthermore, $a c c D$ and ycf2 have been frequently reported as lost or highly variable [3]. 

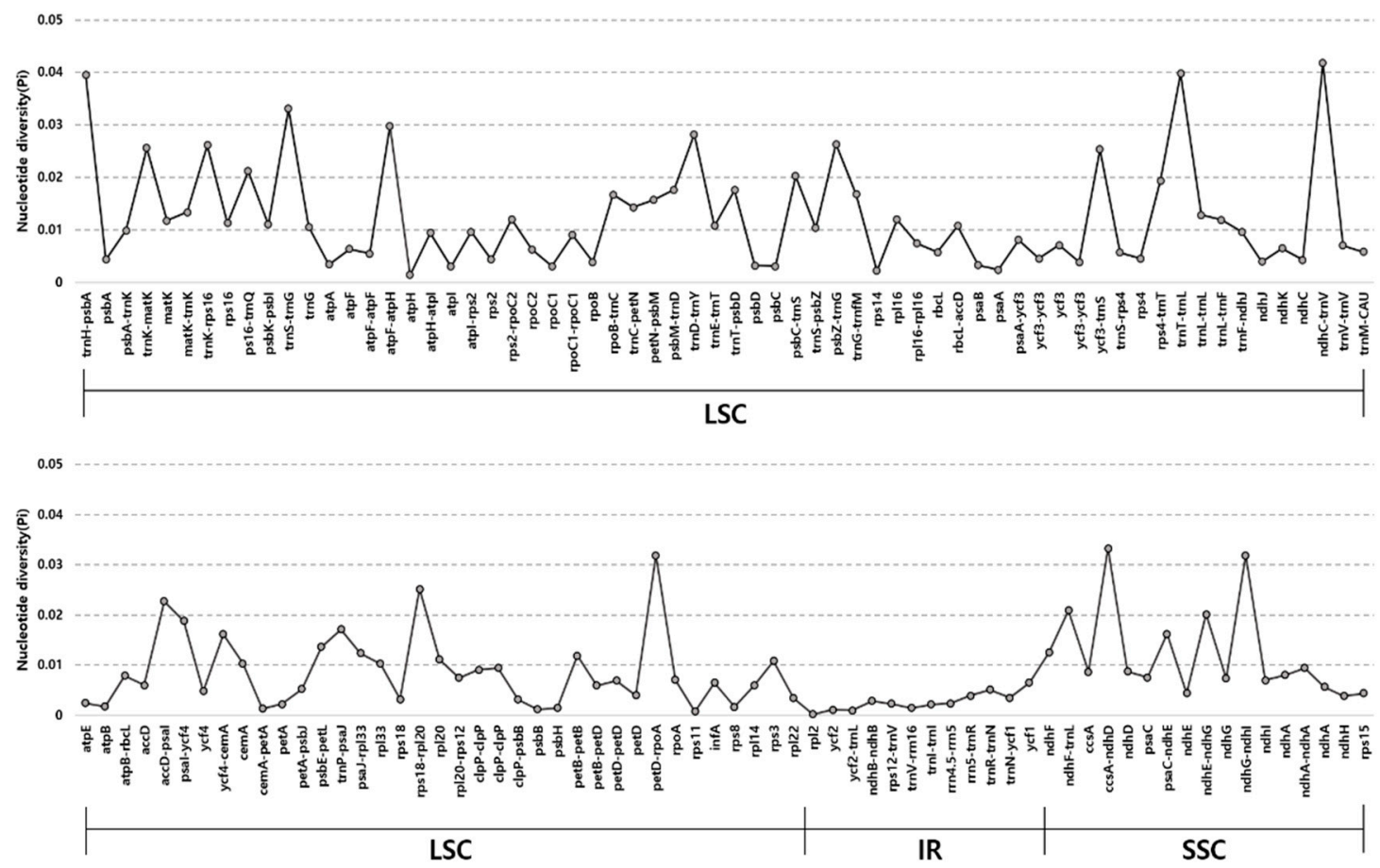

Figure 3. Comparison of nucleotide diversity (Pi) in the cp genomes of six Actaea species, including A. simplex, A. dahurica, A. biternata, A. heracleifolia, A. asiatica, and A. vaginata.

\subsection{Phylogenetic Relationship among Actaea Species}

We determined the phylogenetic relationship of A. simplex, A. biternate, and A. dahurica with other Actaea species within the tribe Cimicifugeae based on two data sets: 65 conserved protein-coding gene sequences (Figure 4) and whole cp genome sequences (Figure S7). In both phylogenetic trees, Actaea species were clustered, consistent with the Actaea sectional classification of Compton et al. [12]. Five out of seven nodes in both phylogenetic trees showed maximum likelihood (ML) bootstrap (BS) values of $100 \%$ and Bayesian inference (BI) posterior probability (PP) values of 1.0. A. heracleifolia and A. simplex clustered within a monophyletic group, showed a sister relationship with $A$. dahurica. A. vaginata showed a paraphyletic relationship with the other five Actaea species, consistent with the APG IV system of classification [41]. Compton et al. [12] reclassified Actaea to include 27 Cimicifuga species, based on morphology, nuclear ITS region, and cp $t r n L-F$ region, and strongly supported the delimitation of Actaea as seven sections. Our phylogenetic analyses divided Actaea species into four groups, which was consistent with the previous infrageneric classification (Actaea sections Actaea, Dichanthera, Pityrosperma, and Souliea). Recently, phylogenetic analysis of 35 species within Ranunculaceae, based on cp genome sequences, showed that $A$. dahurica and $A$. vaginata formed a monophyletic cluster [11]. However, our results indicated that $A$. dahurica and $A$. vaginata, both of which are follicular species, were distinct, whereas A. biternata and A. asiatica, which produce different fruit types (follicle and berry, respectively), were the closest relatives.

To understand the phylogenetic relationship between Actaea and Cimicifuga, an in-depth investigation of other $\mathrm{CP}$ genomes and reinterpretation of morphological data are needed. We propose that further studies of Actaea with expanded species, including A. japonica from Actaea sect. Pityrosperma and A. erythrocarpa from Actaea sect. Actaea as well as the North American (sect. Podocarpae and Oligocarpae) and Eurasian Actaea (sect. Cimicifugae) species, be considered to evaluate the cp genome trends and their evolution. Overall, these results provide insights into the phylogenetic relationship among species within Cimicifugeae. 


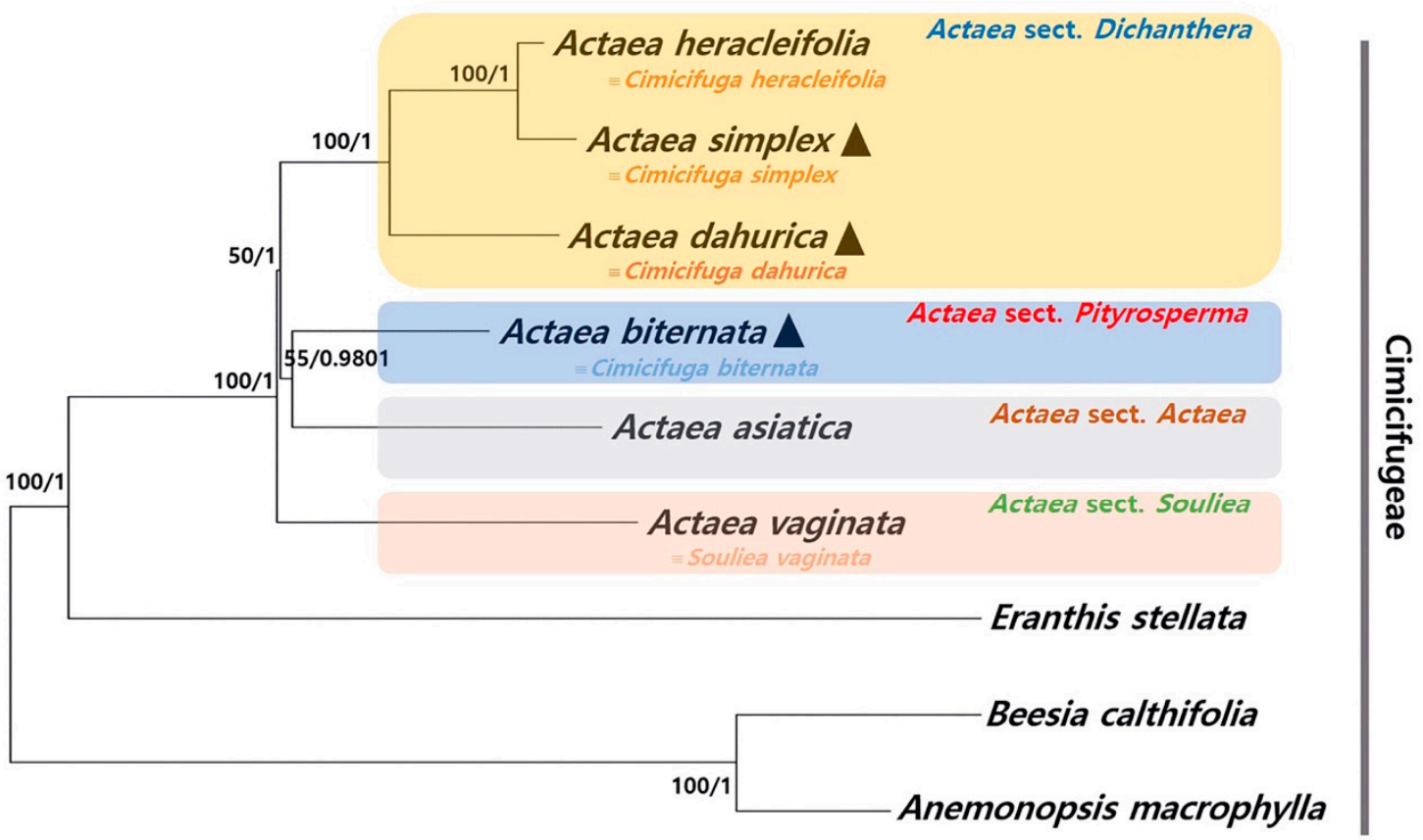

0.0020

Figure 4. Phylogenetic analysis of nine species within the tribe Cimicifugeae. The phylogenetic tree was constructed with the maximum likelihood (ML) method and Bayesian Inference (BI) using 65 conserved protein-coding sequences from six Actaea species and one Eranthis species. Beesia calthifolia and Anemonopsis macrophylla were used as outgroups. ML topology is shown with bootstrap (BS) values $(\%)$, and BI posterior probability (PP) values at each node. Black triangles indicate the cp genomes of three Actaea species investigated in this study.

\subsection{Development of an Indel Marker for the Identification of Authentic Cimicifugae Rhizoma}

We detected sequence variations in the cp genomes of five Actaea species to distinguish between authentic and adulterated Cimicifugae Rhizoma. Results showed that cp genomes of A. biternata and $A$. asiatica, which are usually found as adulterants in Cimicifugae Rhizoma, carry 67- and 39-bp insertions, respectively, in the rps16-trnQ-UUG region, unlike $A$. heracleifolia, A. simplex, and A. dahurica, sources of authentic Cimicifugae Rhizoma. Indel primers were designed flanking rps16 and trnQ-UUG genes (Table 2). The ACT primers successfully amplified cpDNA from five Actaea species (Figure 5). Twenty accessions of five Actaea were used and successfully distinguished between authentic sources of Cimicifugae Rhizoma (A. heracleifolia, A. simplex and A. dahurica) and adulterants (A. biternata and A. asiatica) (Figure 5 and Table S9). We also detected copy number variations of tandem repeats in cp genomes of Actaea. While A. heracleifolia, A. simplex, and A. dahurica contained no tandem repeats, A. biternata and $A$. asiatica contained two and three copies of tandem repeats, respectively, indicating species-specific variation. Unfortunately, we did not detect copy number variation of tandem repeats within Actaea sect. Dichanthera, which was not found any divergence sequence for distinguishing among three Actaea species, A. heracleifolia, A. simplex and A. dahurica at PCR-based approach resulted in using 12 accessions. Samples used in this study were obtained from diverse native regions in Korea. To develop species-specific markers, a larger collection of samples is needed. 
Table 2. Primers used to develop the Actaea (ACT) indel marker.

\begin{tabular}{ccc}
\hline Primer Name & Primer Sequence $\left(5^{\prime} \rightarrow \mathbf{3}^{\prime}\right)$ & Position \\
\hline ACT-F & TCA GCA TCG AGT TAG TAC CGT & \multirow{2}{*}{ rps16-trnQ-UUG } \\
\cline { 1 - 2 } ACT-R & CCG AAT CGA GTA CCG ATG ACA & \\
\hline
\end{tabular}

A. biternata $67 \mathrm{bp}$ - insertion

A. asiatica $39 \mathrm{bp}$ - insertion
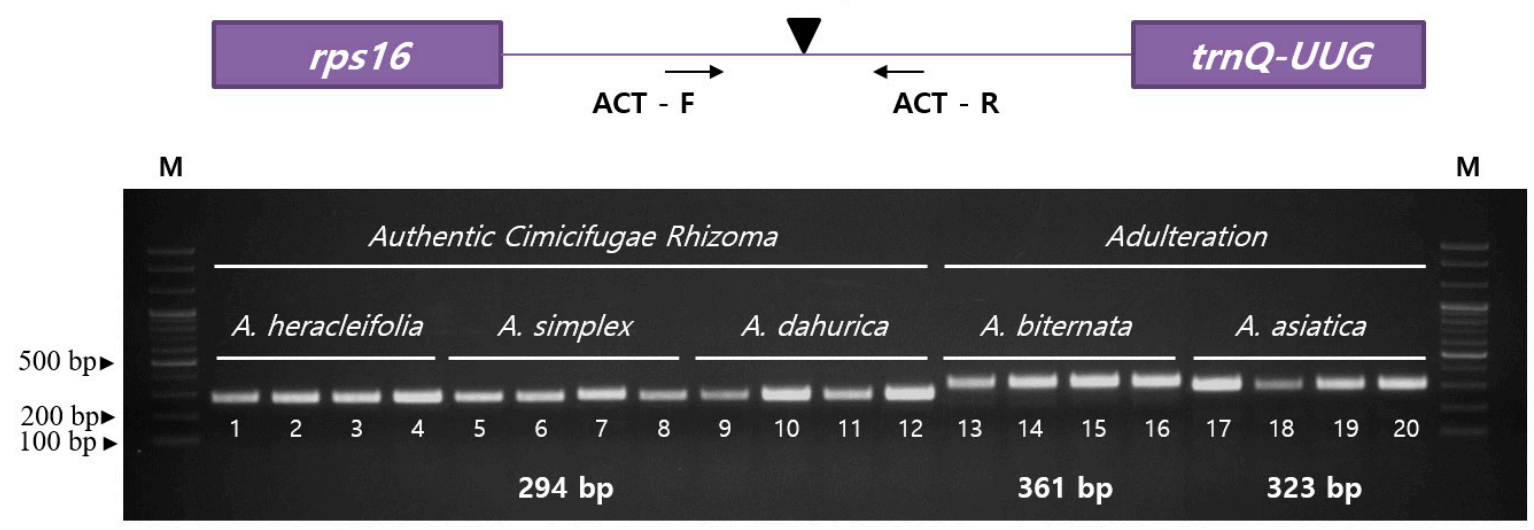

Figure 5. PCR amplification of the ACT indel marker in five Actaea species. The numbers indicate 20 accessions. Accession details are provided in Table S9.

Indel variations have played an important role in plant genome evolution and are responsible for genomic rearrangements via slipped strand mispairing and stem-loop secondary structures via intramolecular recombination [42-45]. Previously, seeds of Ipomoea nil and I. purpurea, components of the herbal medicine Pharbitidis Semen, have been successfully distinguished from those of other related Ipomoea species using indel markers based on variation in cp genomes [27]. Indel markers have also been used for species identification in the genera Chenopodium (to distinguish between C. quinoa and C. album) [46] and Fagopyrum (to distinguish between F. tatricum and F. esculentum) [47]. Thus, indel markers have been successfully used for species identification and herbal medicine authentication, thus overcoming the limitation of conventional methods such as DNA barcoding. The ACT marker could be useful for the authentication of A. heracleifolia, A. simplex, and A. dahurica and authentication of Cimicifugae Rhizoma.

\section{Materials and Methods}

\subsection{Plant Material}

Plant material used in this study was collected from natural populations in Korea. Representative fresh leaves of $A$. simplex $\left(37^{\circ} 09^{\prime} 00.1^{\prime \prime} \mathrm{N}\right.$ and $\left.128^{\circ} 54^{\prime} 14.3^{\prime \prime} \mathrm{E}\right)$, A. dahurica $\left(37^{\circ} 07^{\prime} 10.0^{\prime \prime} \mathrm{N}\right.$ and $\left.128^{\circ} 56^{\prime} 24.9^{\prime \prime} \mathrm{E}\right)$, and A. biternata $\left(33^{\circ} 21^{\prime} 59.1^{\prime \prime} \mathrm{N}\right.$ and $126^{\circ} 26^{\prime} 21.0^{\prime \prime} \mathrm{E}$ ) were used for cp genome sequencing. These samples were assigned identification numbers, and voucher specimens were deposited in the Korean Herbarium of Standard Herbal Resources (Index Herbarium code KIOM) at the Korea Institute of Oriental Medicine (KIOM, Naju, Korea). Plant samples used for cp genome sequencing and indel marker validation are listed in Table S9.

\subsection{Genome Sequencing and Assembly}

DNA was extracted from leaf samples using DNeasy Plant Maxi Kit (Qiagen, Valencia, CA, USA), according to the manufacturer's instructions. Illumina short-insert paired-end sequencing libraries were constructed and sequenced using the MiSeq platform (Illumina, San Diego, CA, USA). De novo and reference-guided strategies were used to assemble cp genomes. High quality paired-end reads 
were assembled using the CLC genome assembler (ver. 4.06 beta; CLC Inc., Rarhus, Denmark) with default parameters. Highly similar contigs representing cp genome sequences were retrieved using Nucmer [48], and mapped to the reference cp genomes of Megaleranthis saniculifolia (FJ597983) and A. asiatica (NC_041525). We determined the order of aligned contigs according to the reference $c p$ genome, and gaps were filled using Short Oligonucleotide Analysis Package (SOAP) de novo gap closer, based on the raw reads to the assembly [49]. Four cp junctions (LSC/IRa, IRa/SSC, SSC/IRb, and IRb/LSC) were confirmed by PCR-based sequencing using sequence-specific primers to validate correct genome assembly (Table S2). Finally, raw reads were mapped onto the complete cp genome sequences using BWA ver. 0.7.25 [50].

\subsection{Genome Annotation and Comparative Analysis}

The DOGMA and GeSeq [51,52] tools were used to annotate the three complete Actaea, A. simples, A. dahurica, and $A$. biternata, cp genomes. Start and stop codons of protein-coding sequences were manually corrected based on reference genomes (FJ597983 and NC_041525). The tRNAscan-SE 1.21 [53] was used to obtain and identify tRNA genes. The circular gene maps were constructed using the OrganellarGenomeDRAW (OGDRAW) [54]. MEGA6 was analyzed to GC content and codon usage of cp genomes [55]. MAUVE V2.3.1 was used to identify local collinear blocks of 6 Actaea species (A. heracleifolia, A. simplex, A. dahurica, A. biternata, A. asiatica, and A. vaginata) [56]. Nucleotide diversity (Pi) among the 6 Actaea species was calculated using DnaSP version 6.1 [57]. Pi value of 0 was excluded. Values of $\mathrm{Ka}$, $\mathrm{Ks}$ and $\mathrm{Ka} / \mathrm{Ks}$ ratio were estimated using the KaKs Calculator ver. 2.0 [58].

\subsection{Repeat Analysis}

The MISA tool was used to detect SSRs in cp genomes of A. simplex, A. dahurica, and A. biternata [33], with the minimum number of repeats set at 10, 5, 4, 3, 3, and 3 for mono-, di-, tri-, tetra-, penta-, and hexanucleotide SSRs, respectively. Tandem repeat finder was used to identify tandem and palindromic repeats $(\geq 20 \mathrm{bp}$ ) with the following parameters: Minimum alignment score $=50$; maximum period size $=500$; repeat identity $\geq 90 \%$ [34].

\subsection{Phylogenetic Analysis}

In this study, 2 matrices were used for phylogenetic analysis: 1) A total of 65 conserved protein-coding sequences in $9 \mathrm{cp}$ genomes aligned over a length of 66,374 bp; and 2) whole cp genomes. Six cp genome sequences within the tribe Cimicifugeae were downloaded from NCBI (Table S10). Beesia calthifolia and Anemonopsis macrophylla were used as outgroups. Using MAFFT, 65 protein-coding genes and whole cp genomes were aligned [59], the gaps in the alignment were stripped using BioEdit [60]. The best-fitting model was selected based on the Akaike Information Content (AIC) using JModeltest V2.1.10 [61]. The GTR + I + G model was applied to protein-coding genes (Table S11), and the TVM + I $+\mathrm{G}$ model was used for whole cp genomes (Table S12). ML analysis was performed using MEGA6 [55], and branch support was calculated with 1000 bootstrap replicates. BI analysis was performed in MrBayes 3.2.2 [62] using the settings as following: Two independent Markov Chain Monte Carlo (MCMC) runs were performed for 1 million generations with samples every 1000 generations, the first $25 \%$ of trees were discarded as burn-in.

\subsection{Development and Validation of the ACT Indel Marker}

The indel region was detected based on mVISTA similarities and aligned sequences. To amplify these regions, primers were designed using Primer-BLAST (NCBI). ACT indel marker was amplified from $20 \mathrm{ng}$ of genomic DNA in a $20-\mu \mathrm{L}$ reaction volume containing Solg ${ }^{\mathrm{TM}} 2 \mathrm{X}$ Taq PCR Smart Mix 1 (Solgent, Daejeon, Korea) and 10 pmol of each primer (BIONICS, Seoul, Korea). Amplification of ACT was conducted on a C1000 Touch ${ }^{\mathrm{TM}}$ Thermal Cycler (Bio-Rad Laboratories, Inc., Hercules, CA, USA) with the following conditions: Initial denaturation at $95^{\circ} \mathrm{C}$ for $2 \mathrm{~min}$, followed by 35 cycles of denaturation at $95{ }^{\circ} \mathrm{C}$ for $40 \mathrm{~s}$, annealing at $60{ }^{\circ} \mathrm{C}$ for $40 \mathrm{~s}$, and extension at $72{ }^{\circ} \mathrm{C}$ for $50 \mathrm{~s}$ and lastly 
a final extension at $72{ }^{\circ} \mathrm{C}$ for $5 \mathrm{~min}$. PCR products were separated on $2 \%$ agarose gels at $150 \mathrm{~V}$ for 40 min. All samples were obtained from the KIOM herbarium (Table S9).

\section{Conclusions}

In this study, we determined and analyzed the cp genome sequences of $A$. simplex, $A$. dahurica, and $A$. biternata. The cp genomes of all three species were highly conserved about the genomic characterization such as gene content and orientation, and GC content, although local sequence variations were also detected. Additionally, we established phylogenetic relationships among Actaea species using whole cp genome sequences and protein-coding sequences. The results of this study help determine the complex taxonomical classification of Actaea. Furthermore, based on copy number variations of tandem repeats in cp genomes of Actaea species, we developed an indel marker for species identification and authentication of herbal medicines. These results could add to the authentic herbal medicinal material containing $A$. simplex, $A$. dahurica, and $A$. heracleifolia such as Cimicifugae Rhizoma. These cp genome data of Actaea provide useful information to identify medicinal materials and hypothesize systematic and evolutionary works.

Supplementary Materials: Supplementary materials can be found at http://www.mdpi.com/2223-7747/9/2/157/s1. Figure S1: Validation of the complete chloroplast (cp) genomes of three Actaea species, A. simplex, A. dahurica, and $A$. biternata using raw read mapping. LSC, large single copy region; SSC, small single copy region; IRa, inverted repeat $\mathrm{a}$; IRb, inverted repeat $\mathrm{b}$, Figure S2: Codon frequencies and RSCU (relative synonymous codon usage) values of three Actaea species, A. simplex, A. dahurica, and A. biternata. (A) Amino acid frequencies in protein-coding genes. (B) RSCU values of 20 amino acids and stop codons in 78 protein-coding genes, Figure S3: Distribution of simple sequence repeats (SSRs) in cp genomes of three Actaea species, Figure S4: Comparison of complete $\mathrm{cp}$ genomes of six Actaea species using the MAUVE algorithm, Figure S5: Comparison of the position of junctions between the large single copy (LSC) region, inverted repeat (IR) regions (IRa and IRb) and small single copy (SSC) region in the cp genomes of six Actaea species, Figure S6: Comparison of non-synonymous substitution rate $(\mathrm{Ka})$, synonymous substitution rate $(\mathrm{Ks})$, and $\mathrm{Ka} / \mathrm{Ks}$ ratio of 67 conserved protein-coding genes among the cp genomes of A. simplex, A. dahurica, and A. biternata, Figure S7: Phylogenetic analysis of nine species within the tribe Cimicifugeae, Table S1: Raw read and assembly information of the chloroplast (cp) genomes of three Actaea species, Table S2: Primers used for PCR-based sequence validation of cp junctions in three Actaea species, Table S3: Information of PCR-based sequencing, Table S4: Genes present in the cp genomes of three Actaea species, Table S5: Gene introns in cp genomes of three Actaea species, Table S6: Tandem repeats detected in the cp genome of A. simplex, Table S7: Tandem repeats detected in the cp genome of $A$. dahurica, Table S8: Tandem repeats detected in the cp genome of $A$. biternata, Table S9: List of Actaea accession numbers used in this study, Table S10: Accession numbers of $\mathrm{cp}$ genomes used for phylogenetic analysis, Table S11: Selection of the best-fitting substitution model for 65 conserved genes using jModelTest, Table S12: Selection of the best-fitting substitution model for whole cp genomes using jModelTest.

Author Contributions: Experimental design, I.P.; collection and identification of plant material, J.-H.S., S.Y., and B.C.M.; experiment execution, I.P.; genome analysis, I.P.; manuscript draft preparation, I.P.; manuscript review, I.P. and B.C.M. All authors contributed to the experiments and approved the final manuscript.

Funding: This research was funded by a grant on the Applicational Development of Standardized Herbal Resources (KSN1911420) from the Korea Institute of Oriental Medicine (KIOM), Republic of Korea.

Conflicts of Interest: The authors declare no conflict of interest.

\section{References}

1. Wicke, S.; Schneeweiss, G.M.; de Pamphilis, C.W.; Muller, K.F.; Quandt, D. The evolution of the plastid chromosome in land plants: Gene content, gene order, gene function. Plant Mol. Biol. 2011, 76, $273-297$. [CrossRef] [PubMed]

2. Jansen, R.K.; Ruhlman, T.A. Plastid genomes of seed plants. In Genomics of Chloroplasts and Mitochondria; Springer: Dordrecht, The Netherlands, 2012; pp. 103-126.

3. Daniell, H.; Lin, C.S.; Yu, M.; Chang, W.J. Chloroplast genomes: Diversity, evolution, and applications in genetic engineering. Genome Biol. 2016, 17, 134. [CrossRef] [PubMed]

4. Nie, X.; Lv, S.; Zhang, Y.; Du, X.; Wang, L.; Biradar, S.S.; Tan, X.; Wan, F.; Weining, S. Complete chloroplast genome sequence of a major invasive species, crofton weed (Ageratina adenophora). PLoS ONE 2012, 7, e36869. [CrossRef] [PubMed] 
5. Faure, S.; Noyer, J.L.; Carreel, F.; Horry, J.P.; Bakry, F.; Lanaud, C. Maternal inheritance of chloroplast genome and paternal inheritance of mitochondrial genome in bananas (Musa acuminata). Curr. Genet. 1994, 25, 265-269. [CrossRef] [PubMed]

6. Sasaki, T.; Yukawa, Y.; Miyamoto, T.; Obokata, J.; Sugiura, M. Identification of RNA editing sites in chloroplast transcripts from the maternal and paternal progenitors of tobacco (Nicotiana tabacum): Comparative analysis shows the involvement of distinct trans-factors for ndhB editing. Mol. Biol. Evol. 2003, 20, 1028-1035. [CrossRef] [PubMed]

7. Jansen, R.K.; Cai, Z.; Raubeson, L.A.; Daniell, H.; Depamphilis, C.W.; Leebens-Mack, J.; Muller, K.F.; Guisinger-Bellian, M.; Haberle, R.C.; Hansen, A.K.; et al. Analysis of 81 genes from 64 plastid genomes resolves relationships in angiosperms and identifies genome-scale evolutionary patterns. Proc. Natl. Acad. Sci. USA 2007, 104, 19369-19374. [CrossRef] [PubMed]

8. Parks, M.; Cronn, R.; Liston, A. Increasing phylogenetic resolution at low taxonomic levels using massively parallel sequencing of chloroplast genomes. BMC Biol. 2009, 7, 84. [CrossRef]

9. Caron, H.; Dumas, S.; Marque, G.; Messier, C.; Bandou, E.; Petit, R.J.; Kremer, A. Spatial and temporal distribution of chloroplast DNA polymorphism in a tropical tree species. Mol. Ecol. 2000, 9, 1089-1098. [CrossRef]

10. Park, I.; Yang, S.; Kim, W.J.; Noh, P.; Lee, H.O.; Moon, B.C. Complete chloroplast genome of Actaea heracleifolia (Kom.) J. Compton. Mitochondrial DNA B Resour. 2018, 3, 939-940. [CrossRef]

11. Zhai, W.; Duan, X.; Zhang, R.; Guo, C.; Li, L.; Xu, G.; Shan, H.; Kong, H.; Ren, Y. Chloroplast genomic data provide new and robust insights into the phylogeny and evolution of the Ranunculaceae. Mol. Phylogenet. Evol. 2019, 135, 12-21. [CrossRef]

12. Compton, J.A.; Culham, A.; Jury, S.L. Reclassification of Actaea to include Cimicifuga and Souliea (Ranunculaceae): Phytogeny inferred from morphology, nrDNA ITS, and cpDNA trnL-F sequence variation. Taxon 1998, 47, 593-634. [CrossRef]

13. Amman, J. Stirpium Rariorum in Imperio Rutheno Sponte Provenientium Icones et Descriptiones: Instar Supplementi ad Commentar. Acad. Scient. Imper; ex Typographia Academiae Scientiarum: Saint Petersburg, Russia, 1739.

14. Wang, W. Notes on the genus Clematis (Ranunculaceae)(IV). Acta Phytotaxon. Sin. 2001, 39, 1-19.

15. Tamura, M. A new classification of the family Ranunculaceae 2. Acta Phytotaxon. Geobot. 1991, 42, 177-187.

16. Tamura, M. Ranunculaceae. In Flowering Plants-Dicotyledons; Springer: Cham, Switzerland, 1993; pp. 563-583.

17. Compton, J.; Culham, A.; Gibbings, J.; Jury, S. Phylogeny of Actaea including Cimicifuga (Ranunculaceae) inferred from nrDNA ITS sequence variation. Biochem. Syst. Ecol. 1998, 26, 185-197. [CrossRef]

18. Luo, J.P.; Wang, L.; Ren, C.; Yang, Q.E.; Yuan, Q. Taxonomic notes on Cimicifuga nanchuanensis (Ranunculaceae), a hitherto imperfectly known species from China. Nord. J. Bot. 2016, 34, 87-101. [CrossRef]

19. Korea Institute of Oriental Medicine (KIOM). Defining Dictionary for Medicinal Herbs. 2019. Available online: http://boncho.kiom.re.kr/codex/ (accessed on 2 August 2019).

20. Liu, Y.-R.; Wu, Z.-J.; Li, C.-T.; Xi, F.-M.; Sun, L.-N.; Chen, W.-S. Heracleifolinosides A-F, new triterpene glycosides from Cimicifuga heracleifolia, and their inhibitory activities against hypoxia and reoxygenation. Planta Med. 2013, 79, 301-307. [CrossRef]

21. Yim, S.-H.; Kim, H.J.; Park, S.-H.; Kim, J.; Williams, D.R.; Jung, D.-W.; Lee, I.-S. Cytotoxic caffeic acid derivatives from the rhizomes of Cimicifuga heracleifolia. Arch. Pharm. Res. 2012, 35, 1559-1565. [CrossRef]

22. Lee, J.H.; Cuong, T.D.; Kwack, S.J.; Seok, J.H.; Lee, J.K.; Jeong, J.Y.; Woo, M.-H.; Choi, J.S.; Lee, H.K.; Min, B.S. Cycloartane-type triterpene glycosides from the rhizomes of Cimicifuga heracleifolia and their anticomplementary activity. Planta Med. 2012, 78, 1391-1394. [CrossRef]

23. Moon, B.C.; Choi, G.; Yuan, Y. Origins of herbal medicines and adulterants in Korea and China. Korea Inst. Orient. Med. 2017 1, 117.

24. Park, S.; Jansen, R.K.; Park, S. Complete plastome sequence of Thalictrum coreanum (Ranunculaceae) and transfer of the rpl32 gene to the nucleus in the ancestor of the subfamily Thalictroideae. BMC Plant Biol. 2015, 15, 40. [CrossRef]

25. Yang, M.; Zhang, X.; Liu, G.; Yin, Y.; Chen, K.; Yun, Q.; Zhao, D.; Al-Mssallem, I.S.; Yu, J. The complete chloroplast genome sequence of date palm (Phoenix dactylifera L.). PLoS ONE 2010, 5, e12762. [CrossRef] [PubMed] 
26. Raubeson, L.A.; Peery, R.; Chumley, T.W.; Dziubek, C.; Fourcade, H.M.; Boore, J.L.; Jansen, R.K. Comparative chloroplast genomics: Analyses including new sequences from the angiosperms Nuphar advena and Ranunculus macranthus. BMC Genom. 2007, 8, 174. [CrossRef] [PubMed]

27. Park, I.; Yang, S.; Kim, W.J.; Noh, P.; Lee, H.O.; Moon, B.C. The complete chloroplast genomes of six Ipomoea species and indel marker development for the discrimination of authentic Pharbitidis Semen (Seeds of I. nil or I. purpurea). Front. Plant Sci. 2018, 9, 965. [CrossRef] [PubMed]

28. Wang, Y.; Zhan, D.F.; Jia, X.; Mei, W.L.; Dai, H.F.; Chen, X.T.; Peng, S.Q. Complete chloroplast genome sequence of Aquilaria sinensis (Lour.) Gilg and evolution analysis within the Malvales order. Front. Plant Sci. 2016, 7, 280. [CrossRef]

29. Park, I.; Yang, S.; Kim, W.J.; Noh, P.; Lee, H.O.; Moon, B.C. Authentication of herbal medicines Dipsacus asper and Phlomoides umbrosa using DNA barcodes, chloroplast genome, and sequence characterized amplified region (SCAR) marker. Molecules 2018, 23, 1748. [CrossRef]

30. Ivanova, Z.; Sablok, G.; Daskalova, E.; Zahmanova, G.; Apostolova, E.; Yahubyan, G.; Baev, V. Chloroplast genome analysis of resurrection tertiary relict Haberlea rhodopensis highlights genes important for desiccation stress response. Front. Plant Sci. 2017, 8, 204. [CrossRef]

31. Powell, W.; Morgante, M.; McDevitt, R.; Vendramin, G.G.; Rafalski, J.A. Polymorphic simple sequence repeat regions in chloroplast genomes: Applications to the population genetics of pines. Proc. Natl. Acad. Sci. USA 1995, 92, 7759-7763. [CrossRef]

32. Dong, W.; Xu, C.; Cheng, T.; Lin, K.; Zhou, S. Sequencing angiosperm plastid genomes made easy: A complete set of universal primers and a case study on the phylogeny of Saxifragales. Genome Biol. Evol. 2013, 5, 989-997. [CrossRef]

33. Beier, S.; Thiel, T.; Munch, T.; Scholz, U.; Mascher, M. MISA-Web: A web server for microsatellite prediction. Bioinformatics 2017, 33, 2583-2585. [CrossRef]

34. Benson, G. Tandem repeats finder: A program to analyze DNA sequences. Nucleic Acids Res. 1999, 27, 573-580. [CrossRef]

35. Group, C.P.W. A DNA barcode for land plants. Proc. Natl. Acad. Sci. USA 2009, 106, 12794-12797. [CrossRef] [PubMed]

36. Park, I.; Kim, W.J.; Yang, S.; Yeo, S.M.; Li, H.; Moon, B.C. The complete chloroplast genome sequence of Aconitum coreanum and Aconitum carmichaelii and comparative analysis with other Aconitum species. PLoS ONE 2017, 12, e0184257. [CrossRef] [PubMed]

37. Redwan, R.M.; Saidin, A.; Kumar, S.V. Complete chloroplast genome sequence of MD-2 pineapple and its comparative analysis among nine other plants from the subclass Commelinidae. BMC Plant Biol. 2015, 15, 196. [CrossRef] [PubMed]

38. Rousseau-Gueutin, M.; Huang, X.; Higginson, E.; Ayliffe, M.; Day, A.; Timmis, J.N. Potential functional replacement of the plastidic acetyl-CoA carboxylase subunit $(\mathrm{accD})$ gene by recent transfers to the nucleus in some angiosperm lineages. Plant Physiol. 2013, 161, 1918-1929. [CrossRef] [PubMed]

39. Thode, V.A.; Lohmann, L.G. Comparative chloroplast genomics at low taxonomic levels: A case study using Amphilophium (Bignonieae, Bignoniaceae). Front. Plant Sci. 2019, 10, 796. [CrossRef] [PubMed]

40. Firetti, F.; Zuntini, A.R.; Gaiarsa, J.W.; Oliveira, R.S.; Lohmann, L.G.; Van Sluys, M.A. Complete chloroplast genome sequences contribute to plant species delimitation: A case study of the Anemopaegma species complex. Am. J. Bot. 2017, 104, 1493-1509. [CrossRef]

41. Chase, M.W.; Christenhusz, M.; Fay, M.; Byng, J.; Judd, W.S.; Soltis, D.; Mabberley, D.; Sennikov, A.; Soltis, P.S.; Stevens, P.F. An update of the Angiosperm Phylogeny Group classification for the orders and families of flowering plants: APG IV. Bot. J. Linn. Soc. 2016, 181, 1-20.

42. Park, I.; Yang, S.; Kim, W.J.; Song, J.H.; Lee, H.S.; Lee, H.O.; Lee, J.H.; Ahn, S.N.; Moon, B.C. Sequencing and comparative analysis of the chloroplast genome of Angelica polymorpha and the development of a novel indel marker for species identification. Molecules 2019, 24, 1038. [CrossRef]

43. Levinson, G.; Gutman, G.A. Slipped-strand mispairing: A major mechanism for DNA sequence evolution. Mol. Biol. Evol. 1987, 4, 203-221. [CrossRef]

44. Kelchner, S.A. The evolution of non-coding chloroplast DNA and its application in plant systematics. Ann. Mo. Bot. Gard. 2000, 87, 482-498. [CrossRef] 
45. Ogihara, Y.; Terachi, T.; Sasakuma, T. Intramolecular recombination of chloroplast genome mediated by short direct-repeat sequences in wheat species. Proc. Natl. Acad. Sci. USA 1988, 85, 8573-8577. [CrossRef] [PubMed]

46. Hong, S.Y.; Cheon, K.S.; Yoo, K.O.; Lee, H.O.; Cho, K.S.; Suh, J.T.; Kim, S.J.; Nam, J.H.; Sohn, H.B.; Kim, Y.H. Complete chloroplast genome sequences and comparative analysis of Chenopodium quinoa and C. album. Front. Plant Sci. 2017, 8, 1696. [CrossRef] [PubMed]

47. Cho, K.S.; Yun, B.K.; Yoon, Y.H.; Hong, S.Y.; Mekapogu, M.; Kim, K.H.; Yang, T.J. Complete chloroplast genome sequence of tartary buckwheat (Fagopyrum tataricum) and comparative analysis with common buckwheat (F. esculentum). PLoS ONE 2015, 10, e0125332. [CrossRef] [PubMed]

48. Delcher, A.L.; Salzberg, S.L.; Phillippy, A.M. Using MUMmer to identify similar regions in large sequence sets. Curr. Protoc. Bioinform. 2003, 0, 10.3.1-10.3.18. [CrossRef] [PubMed]

49. Luo, R.; Liu, B.; Xie, Y.; Li, Z.; Huang, W.; Yuan, J.; He, G.; Chen, Y.; Pan, Q.; Liu, Y.; et al. SOAPdenovo2: An empirically improved memory-efficient short-read de novo assembler. Gigascience 2012, 1, 18. [CrossRef] [PubMed]

50. Li, H.; Durbin, R. Fast and accurate long-read alignment with Burrows-Wheeler transform. Bioinformatics 2010, 26, 589-595. [CrossRef]

51. Wyman, S.K.; Jansen, R.K.; Boore, J.L. Automatic annotation of organellar genomes with DOGMA. Bioinformatics 2004, 20, 3252-3255. [CrossRef]

52. Tillich, M.; Lehwark, P.; Pellizzer, T.; Ulbricht-Jones, E.S.; Fischer, A.; Bock, R.; Greiner, S. GeSeq-Versatile and accurate annotation of organelle genomes. Nucleic Acids Res. 2017, 45, W6-W11. [CrossRef]

53. Lowe, T.M.; Eddy, S.R. tRNAscan-SE: A program for improved detection of transfer RNA genes in genomic sequence. Nucleic Acids Res. 1997, 25, 955-964. [CrossRef]

54. Greiner, S.; Lehwark, P.; Bock, R. OrganellarGenomeDRAW (OGDRAW) version 1.3.1: Expanded toolkit for the graphical visualization of organellar genomes. Nucleic Acids Res. 2019, 47, W59-W64. [CrossRef]

55. Tamura, K.; Stecher, G.; Peterson, D.; Filipski, A.; Kumar, S. MEGA6: Molecular evolutionary genetics analysis version 6.0. Mol. Biol. Evol. 2013, 30, 2725-2729. [CrossRef] [PubMed]

56. Darling, A.E.; Mau, B.; Perna, N.T. progressiveMauve: Multiple genome alignment with gene gain, loss and rearrangement. PLoS ONE 2010, 5, e11147. [CrossRef] [PubMed]

57. Rozas, J.; Ferrer-Mata, A.; Sanchez-DelBarrio, J.C.; Guirao-Rico, S.; Librado, P.; Ramos-Onsins, S.E.; Sanchez-Gracia, A. DnaSP 6: DNA sequence polymorphism analysis of large data sets. Mol. Biol. Evol. 2017, 34, 3299-3302. [CrossRef] [PubMed]

58. Wang, D.; Zhang, Y.; Zhang, Z.; Zhu, J.; Yu, J. KaKs_Calculator 2.0: A toolkit incorporating gamma-series methods and sliding window strategies. Genom. Proteom. Bioinform. 2010, 8, 77-80. [CrossRef]

59. Katoh, K.; Misawa, K.; Kuma, K.; Miyata, T. MAFFT: A novel method for rapid multiple sequence alignment based on fast Fourier transform. Nucleic Acids Res. 2002, 30, 3059-3066. [CrossRef]

60. Hall, T.A. BioEdit: A user-friendly biological sequence alignment editor and analysis program for Windows 95/98/NT. Nucleic Acids Symp. Ser. 1999, 41, 95-98.

61. Darriba, D.; Taboada, G.L.; Doallo, R.; Posada, D. jModelTest 2: More models, new heuristics and parallel computing. Nat. Methods 2012, 9, 772. [CrossRef]

62. Ronquist, F.; Teslenko, M.; van der Mark, P.; Ayres, D.L.; Darling, A.; Hohna, S.; Larget, B.; Liu, L.; Suchard, M.A.; Huelsenbeck, J.P. MrBayes 3.2: Efficient Bayesian phylogenetic inference and model choice across a large model space. Syst. Biol. 2012, 61, 539-542. [CrossRef]

Sample Availability: Samples of Actaea simplex, Actaea dahurica, Actaea heracleifolia, Actaea biternata, and Actaea asiatica are available from the authors and the herbarium of KIOM.

(C) 2020 by the authors. Licensee MDPI, Basel, Switzerland. This article is an open access article distributed under the terms and conditions of the Creative Commons Attribution (CC BY) license (http://creativecommons.org/licenses/by/4.0/). 